\title{
Effect of Aramid Fabric Orientation Angle on the Mechanical Characteristics of Basalt-Aramid/Epoxy Hybrid Interply Composites
}

\author{
Yogeesha Pai ${ }^{a}$, Dayananda Pai K ${ }^{a}$ (1), M. Vijaya Kini ${ }^{b}$ \\ ${ }^{a}$ Manipal Institute of Technology, Department of Aeronautical and Automobile Engineering, Manipal, \\ Karnataka, India. \\ ${ }^{b}$ Manipal Institute of Technology, Department of Mechanical and Manufacturing Engineering, Manipal, \\ Karnataka, India.
}

Received: April 30, 2021; Revised: July 27, 2021; Accepted: August 1, 2021

\begin{abstract}
This study investigates the effect of aramid fabric orientation angle on the mechanical characteristics of 2-D basalt-aramid/epoxy hybrid interply composites. Hybrid laminates were fabricated by sandwiching three layers of basalt between the aramid face sheets using compression molding process. The composites were tested for tensile, flexural, interlaminar shear strength (ILSS) and Charpy impact test to understand the influence of aramid fabric orientation angle on the mechanical behaviour of hybrid composites. Results show that mechanical strengths of the hybrid laminates decline with increase in the orientation angle of aramid fabric. The $\left(0_{1}{ }_{1}^{\mathrm{A}} / 0_{3}{ }^{\mathrm{B}} / 0_{1}{ }^{\mathrm{A}}\right)$ composite possess the highest tensile, flexural, ILSS and impact properties followed by $\left(30_{1}{ }^{\mathrm{A}} / 0_{3}{ }^{\mathrm{B}} / 30_{1}{ }^{\mathrm{A}}\right)$ and $\left(45_{1}{ }^{\mathrm{A}} / 0_{3}{ }^{\mathrm{B}} / 45_{1}{ }^{\mathrm{A}}\right)$ composites. The fractured samples were analysed to identify the failure modes using scanning electron microscope $(\mathrm{SEM})$ and optical microscope. The examination revealed that primary reason for $\left(30_{1}^{\mathrm{A}} / 0_{3}^{\mathrm{B}} / 30_{1}^{\mathrm{A}}\right)$ and $\left(45_{1} \mathrm{~A} / \mathrm{O}_{3}^{\mathrm{B}} / 45_{1}^{\mathrm{A}}\right)$ specimen failure was due to the delamination, fibre pull out and matrix crack. Strong interfacial bonding was observed between the fibre and matrix in case of $\left(0_{1}{ }^{\mathrm{A}} / 0_{3}{ }^{\mathrm{B}} / 0_{1}{ }^{\mathrm{A}}\right)$ composites.
\end{abstract}

Keywords: Hybrid composites, Fibre orientation angle, Compression molding, Mechanical characterisation.

\section{Introduction}

Composites are made of two or more constituents with distinctive physical and chemical properties, bonded together to develop a new material of unique properties. In recent years, fibre reinforced polymer composites (FRP) are gaining more popularity among aerospace, defence and automotive industries because of their higher strength, light weight and enhanced mechanical characteristics as compared to conventional materials ${ }^{1,2}$. Mechanical characteristics of composites are affected by the factors viz. nature of matrix and fibre, fibre volume and orientation, bonding between the fibre and matrix interface etc ${ }^{3,4}$. A popular method employed to enhance the performance of a composite for a specific application is hybridisation. Hybrid composites are one of the most recognised and emerging classes of materials and have led to several technological innovations. Hybridisation has an advantage of offering flexibility to tailor the material properties as per the design requirements. For impact applications, brittle inorganic fibres are always combined with the ductile organic fibres to form hybrid composites such as jute/carbon, palm/glass, aramid /basalt, Kevlar/flax etc ${ }^{5-7}$.

Currently, natural/mineral fibre reinforced composites are gaining attention due to the environmental regulations by authorities. Basalt fibres are mineral fibres extruded from basalt rocks, have recently gained popularity due to their

*e-mail: dayanand.pai@manipal.edu benefits in terms of environmental friendly, nontoxic, natural, inexpensive and good physical/mechanical properties ${ }^{8,9}$. Many studies have reported that glass or carbon fibres can be replaced by basalt fibres due to their increased strength, modulus and better failure strain ${ }^{10,11}$. Basalt is an inorganic fibre, possess high stiffness but have poor impact properties due to its brittle nature. The brittleness of basalt fibres can be improved by hybridising with more ductile fibres such as aramid, which has superior impact resistance, good tensile strength and modulus ${ }^{12}$. Hence, by combining aramid and basalt fibres, hybrid composites can be made having the best properties of parent material and can be used where moderate strength is required.

Bandaru et al. ${ }^{13}$ studied the effect of hybridisation on the mechanical behaviour of Kevlar-basalt hybridised polypropylene composites. Authors reported that hybridisation improved the tensile behaviour and tensile modulus was enhanced by $13.77 \%$ compared to homogeneous Kevlar composites. Sarasini et al. ${ }^{14-16}$ analysed the drop weight impact characteristics of epoxy based composites with basalt/carbon, basalt/glass and basalt/aramid as reinforcement. Results indicated improved flexural behaviour, higher absorption of impact energy for hybrid laminates fabricated with sandwich like arrangement (intercalated) than the non-hybridized configurations. Park and Jang ${ }^{17}$ evaluated the impact response of asymmetric four-layer aramid/glass 
hybrid composites and found that aramid layer position in the hybrid composites influences the impact energy and delaminated area. Higher impact energy absorption was observed due to increase of propagation energy when the aramid layer was placed at the bottom side of the laminates. Vasudevan et al. ${ }^{18}$ investigated the quasi-static characteristics of Kevlar-glass epoxy hybrid composites with the core as glass fibre layers sandwiched between Kevlar layers and reported that composite with outer Kevlar layers oriented at $30^{\circ}$ possess higher tensile and flexural properties but $45^{\circ}$ oriented Kevlar layer composites possess higher percentage elongation. Dorey et al. ${ }^{19}$ conducted quasi-static and drop weight impact tests on Kevlar/epoxy(KFRP), carbon/ epoxy(CFRP) and hybrid carbon-Kevlar/epoxy laminates. Results showed higher quasi static properties for CFRP composites and lower for KFRP composites compared to hybrid laminates, while the reverse trend was displayed in impact loading. The presence of outer Kevlar fibres in hybrid laminates significantly improved the impact properties than CFRP laminates and superior mechanical properties are exhibited than KFRP laminates. They also concluded that hybrid laminates with surface aramid layers perform better as compared to the laminates with inner aramid layers.

Several researchers have investigated the mechanical characteristics of basalt-aramid hybrid composites. The studies have shown that hybrid laminates with surface aramid layers are more effective in controlling the delamination as compared to inner aramid layers. The load carrying central core of basalt laminates $\left(0^{\circ} / 90^{\circ}\right)$ can be safeguarded from damage by placing aramid fabrics as surface plies ${ }^{18}$. The surface aramid layer control delamination by distributing the damage over a larger area from the impacted zone. Abundant literatures are available on this research work but only limited information exist on how the orientation angle of surface aramid layer influence the mechanical strengths of basalt-aramid hybrid composites. Hence, this work is an attempt to study the effect of aramid fabric orientation angle on the tensile, flexural, interlaminar shear strength and impact behaviour of basalt-aramid/epoxy composites. Composites were fabricated using 2-D plain woven aramid fabrics and basalt fabrics with the epoxy resin. Five layered interply composite laminates were prepared for three different orientation angle of aramid fabric using compression molding process. The influence of hybridisation on the mechanical characteristics are evaluated as per the ASTM standards. Further, SEM and optical microscopy analysis were carried out to understand the failure modes.

\section{Materials and Procedures}

\subsection{Materials}

The hybrid composites were fabricated using bidirectional (2D) aramid fabric having areal weight of $480 \mathrm{~g} / \mathrm{m}^{2}$ and bidirectional basalt fabric with areal weight of $400 \mathrm{~g} / \mathrm{m}^{2}$. Fabrics were procured from M/S Composite Tomorrow, India. Chemical products of epoxy (CT/E 556) resin of density $1150 \mathrm{~kg} / \mathrm{m}^{3}$ and hardener (CT/H 951) of density $970 \mathrm{~kg} / \mathrm{m}^{3}$ are used as thermoset matrix material. Table 1 shows the material properties of aramid and basalt fibres.
Table 1. Material properties of aramid and basalt fibres.

\begin{tabular}{ccc}
\hline Property & Aramid fibre & Basalt fibre \\
\hline Density $\left(\mathrm{kg} / \mathrm{m}^{3}\right)$ & 1440 & 2.8 \\
\hline Elastic modulus $(\mathrm{GPa})$ & $>72$ & 89 \\
\hline Elongation at break $(\%)$ & $2.8-4.2$ & 3.15 \\
\hline
\end{tabular}

\subsection{Fabrication of hybrid interply composites}

Three different interply hybrid composites namely, $\left(0{ }_{1}^{\mathrm{A}} / 0_{3}{ }^{\mathrm{B}} / 0_{1}{ }^{\mathrm{A}}\right),\left(30_{1}{ }^{\mathrm{A}} / 0_{3}{ }^{\mathrm{B}} / 30_{1}{ }^{\mathrm{A}}\right)$ and $\left(45_{1}{ }^{\mathrm{A}} / 0_{3}{ }^{\mathrm{B}} / 45_{1}{ }^{\mathrm{A}}\right)$ were prepare using compression molding process. Here, subscripts indicate the number of layers and superscripts indicate the type of material (A-Aramid and B-Basalt). For example, $\left(30_{1}{ }^{\mathrm{A}} / 0_{3} \mathrm{~B} / 30_{1}{ }^{\mathrm{A}}\right)$ laminates were fabricated by placing one aramid layer of $30^{\circ}$ orientation angle as outer and three basalt plies of $0^{\circ}$ orientation angle as inner layers. The mixing ratio for the epoxy resin and hardener was 10:1 as mentioned by the supplier. The composite layup was done on an open mold made of thick mild steel sheet of size $360 \times 360 \mathrm{~mm}$. Hybrid interply laminates of size $300 \mathrm{~mm} \times 300 \mathrm{~mm}$ were prepared by hand layup technique followed by pressing the layup using compression molding machine until a thickness of $2.8 \mathrm{~mm}$ achieved. Precisely machined spacers were used on all the four sides of the mild steel plate to control the thickness of the laminates. Curing is done at room temperature for 24 hours and then panels were cut as per ASTM standards using water jet cutting machine. Figure 1 shows the schematic representation of three laminates.

\subsection{Void fraction}

ASTM D792 20 standard was employed to measure the density of the basalt-aramid hybrid laminates. Samples of $10 \mathrm{~mm} \times 10 \mathrm{~mm}$ size were prepared. Archimedes principle was adopted to determine the experimental density of the laminates. Mass of each sample was measured using electronic weighing scale of least count 0.001 gram. Volume of the samples were calculated by measuring the amount of water displaced. Experimental density can be estimated by the ratio of mass to volume of the sample. Five specimens were chosen from different parts of the laminate for testing and average density was calculated. The theoretical densities of the laminates were calculated from Equation $1^{21}$

$$
\rho_{t h}=\frac{1}{\frac{w_{f}}{\rho_{f}}+\frac{w_{m}}{\rho_{m}}}
$$

The void percentage of the laminate was determined using the following Equation $2^{21}$

$$
\operatorname{Void}(\%)=\frac{\rho_{t h}-\rho_{e x}}{\rho_{e x}} \times 100
$$

Where $w_{\mathrm{f}}, w_{\mathrm{m}}$ are respectively the weight fractions of fibre and matrix. $\rho_{\text {th }}$ and $\rho_{\text {ex }}$ are the theoretical and experimental densities respectively. 


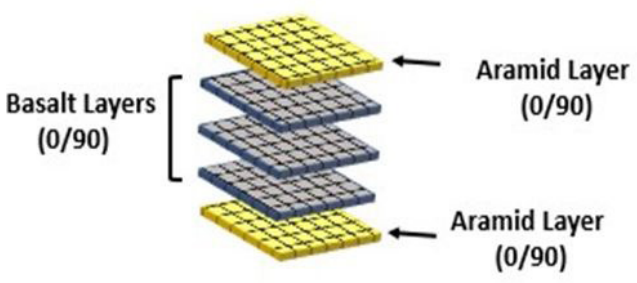

(a)

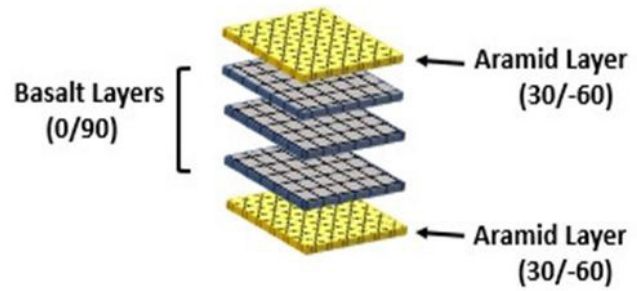

(b)

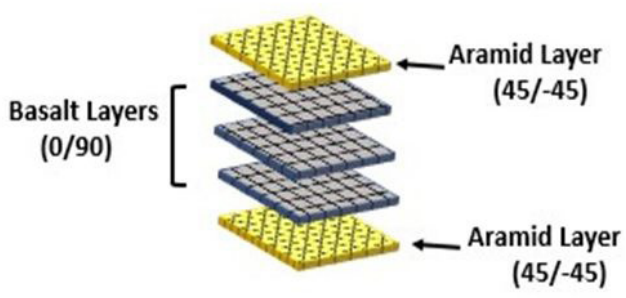

(c)

Figure 1. Schematic representation of (a) $\left(0_{1}{ }^{\mathrm{A}} / \mathrm{O}_{3}{ }^{\mathrm{B}} / 0_{1}{ }^{\mathrm{A}}\right)$ (b) $\left(30_{1}{ }^{\mathrm{A}} / \mathrm{O}_{3}{ }^{\mathrm{B}} / 30_{1}{ }^{\mathrm{A}}\right)$ and (c) $\left(45_{1}{ }^{\mathrm{A}} / 0_{3}{ }^{\mathrm{B}} / 45_{1}{ }^{\mathrm{A}}\right)$ interply hybrid composites

\subsection{Mechanical characterization/Experimental method}

\subsubsection{Tensile test}

The stress-strain behaviour of a composite material can be analysed using tensile test method. Five specimens were prepared as per the standard ASTM D303922 and mounted in the grips of BiSS make computerised universal testing machine of load capacity $50 \mathrm{kN}$ as shown in Figure 2 Specimens were subjected to tensile loads at a constant speed of $2 \mathrm{~mm} / \mathrm{min}$. Applied loads and the displacements data were acquired from the computer connected to the machine. The graphs of stress vs strain were plotted and the Young's modulus was found from the slope of the graph. The ultimate tensile strength corresponding to the maximum load of each specimen and the young's modulus were determined using recorded stress-strain responses.

\subsubsection{Flexural tests}

The flexural strength indicates the ability of a material to resist bending before the fracture. Flexural tests were performed as per ASTM standard D726423. Five samples with standard span-to-thickness ratio of 32:1 and standard width of $13 \mathrm{~mm}$ were cut from the laminate. Specimens were positioned on two supports as a beam and the concentrated load is applied at the mid span at a constant speed of $1 \mathrm{~mm} /$ min employing computerized Universal Testing Machine (FIE make UNITEK-9450 of 50kN load capacity) as shown in Figure 3. The deflection at the mid span of the specimen and corresponding force applied are measured till the failure.

\subsubsection{Interlaminar shear strength test (ILSS)}

The ILSS tests were conducted to determine the short beam strength of the material. Tests were carried out as per the standard ASTM D $2344^{24}$ using Instron universal testing

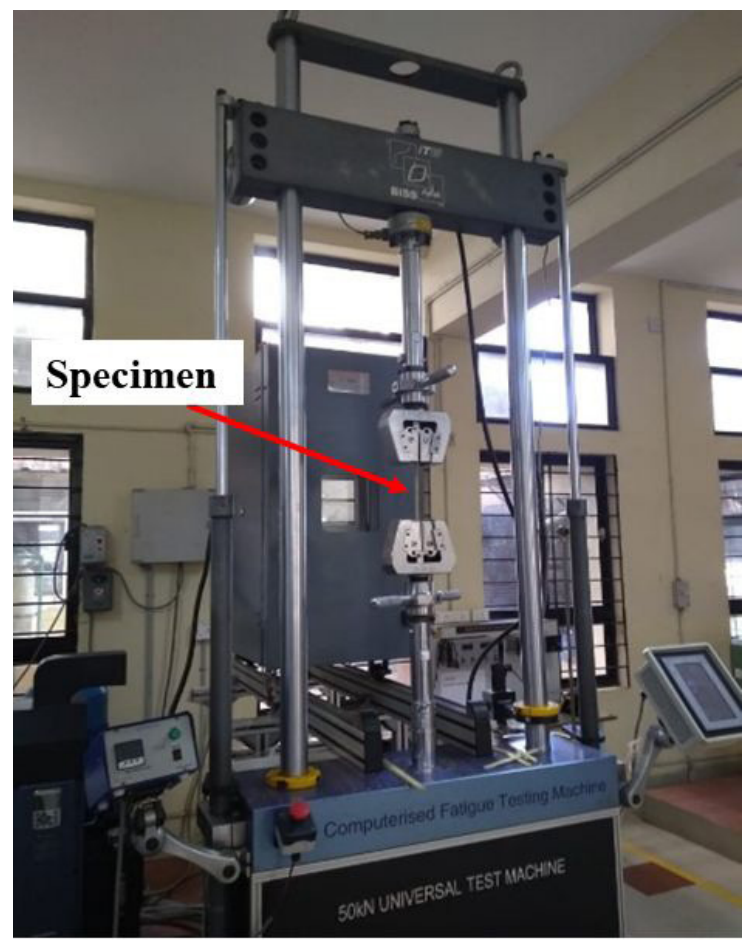

Figure 2. Tensile test setup.

machine of load capacity $50 \mathrm{kN}$ as shown in Figure 4 . The aim of this test method is to determine the shear strength of the specimen by minimising the flexural stresses and maximising the shear stresses between the lamina. As per this standard specimen length should be 6 times the thickness and width should be 2 times the thickness. Five samples of each category were cut and tested using three-point bending method which 
is similar to flexural test with a constant crosshead movement of $1 \mathrm{~mm} / \mathrm{min}$. The loading was measured and recorded until the specimen failed in two pieces or the cross head travel exceeded the nominal thickness of the specimen. The machine is designed such that it stops applying the load if there is a load drop by $30 \%$ as mentioned by ASTM.

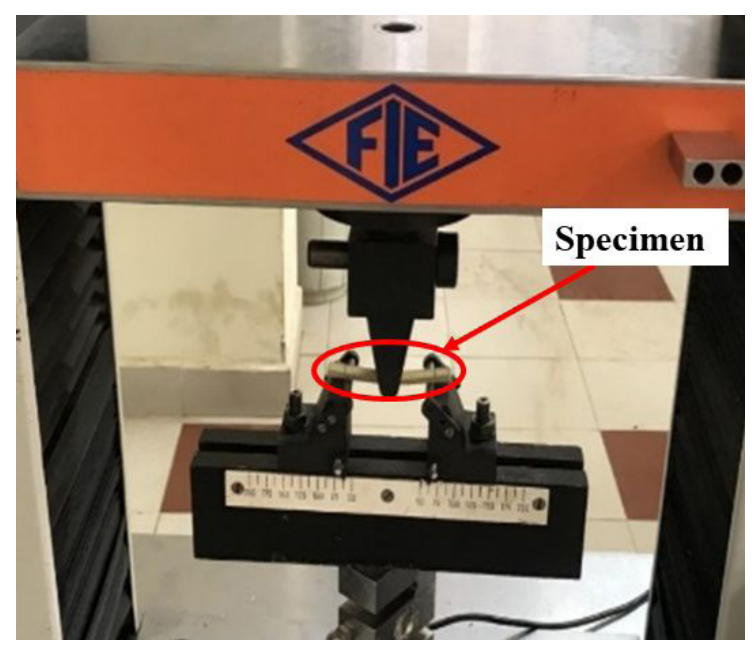

Figure 3. Flexural test setup.

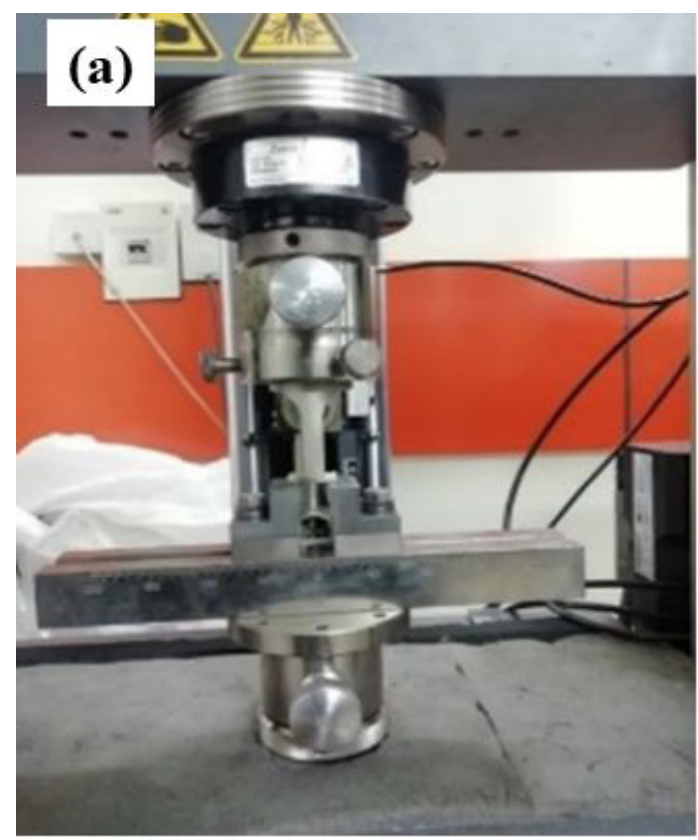

Figure 4. (a) ILSS test setup (b) Enlarged view of the specimen.

\subsubsection{Charpy impact test}

The impact behaviour and impact strength of a composite can be determined using Charpy impact testing method. The tests were executed on a Zwick Roell HIT50P make pendulum impact tester in accordance with ISO $179-1^{25}$ as shown in Figure 5. Five rectangular test specimens from each of the three hybrid composites were cut of size $65 \mathrm{~mm} \times 12.7 \mathrm{~mm}$ $\times 2.8 \mathrm{~mm}$ from the composite panels using water jet cutting machine. The un-notched specimens are placed on the supports in horizontal position and a hammer is dropped to strike the test specimen. The corresponding energy absorbed by the test specimens were measured and recorded.

\section{Results and Discussion}

\subsection{Void percentage}

Voids are the pores that remain unfilled with polymers and fibres in a composite material. Voids are also used as indicative measure for the quality of fabrication. The properties of the composites are affected by the voids present in the composite. Void content in the fabricated laminates are as shown in Table 2.

\subsection{Tensile strength}

The summary of tensile test results as per the ASTM D3039 are given in Table 3. The stress-strain graph signifying

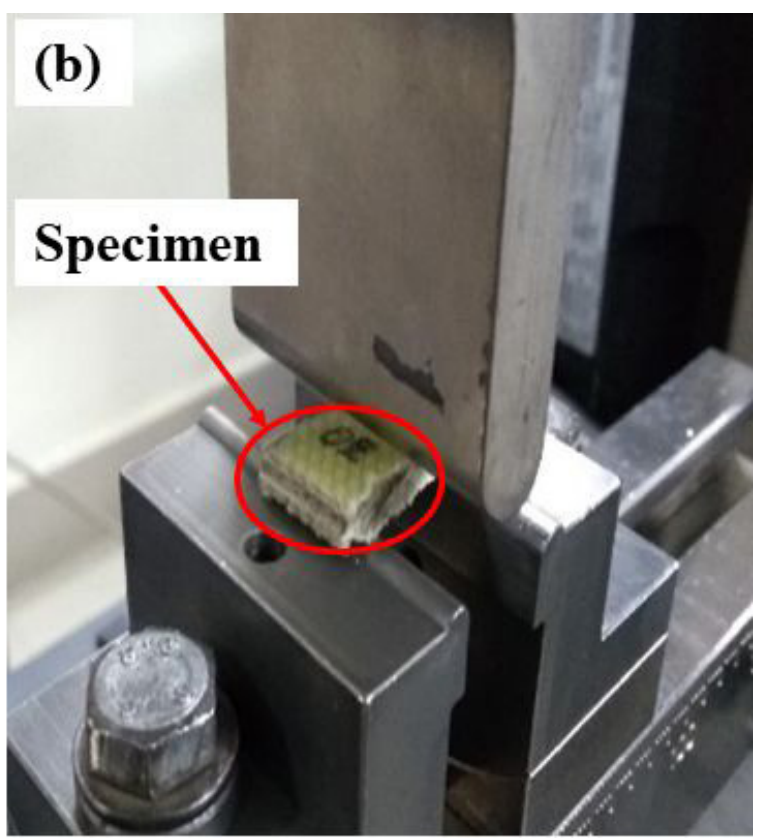

Table 2. Void percentage of composites.

\begin{tabular}{cccc}
\hline Laminate & Density $\left(\right.$ Theoretical) $\left(\mathrm{kg} / \mathrm{m}^{3}\right)$ & Density $($ Experimental $)\left(\mathrm{kg} / \mathrm{m}^{3}\right)$ & Void percentage \\
\hline$\left(0_{1}{ }^{\mathrm{A}} / 0_{3}{ }^{\mathrm{B}} / 0_{1}^{\mathrm{A}}\right)$ & 1910 & 1880 & 1.59 \\
\hline$\left(30_{1}^{\mathrm{A}} / 0_{3}{ }^{\mathrm{B}} / 30_{1}{ }^{\mathrm{A}}\right)$ & 1970 & 1930 & 2.07 \\
\hline$\left(45_{1}{ }^{\mathrm{A}} / 0_{3}{ }^{\mathrm{B}} / 45_{1}{ }^{\mathrm{A}}\right)$ & 1840 & 1780 & 2.70 \\
\hline
\end{tabular}


Table 3. Tensile test results of hybrid composites.

\begin{tabular}{cccc}
\hline Composites & Average tensile strength (MPa) & Average Young's modulus (GPa) & Average strain $(\mathrm{mm} / \mathrm{mm})$ \\
\hline$\left(0_{1}{ }^{\mathrm{A}} / 0_{3}{ }^{\mathrm{B}} / 0_{1}{ }^{\mathrm{A}}\right)$ & $190 \pm 11$ & $6.32 \pm 0.34$ & $0.033 \pm 0.002$ \\
\hline$\left(30_{1}{ }^{\mathrm{A}} /{ }_{3}^{\mathrm{B}} / 30_{1}{ }^{\mathrm{A}}\right)$ & $166 \pm 10$ & $5.59 \pm 0.27$ & $0.035 \pm 0.002$ \\
\hline$\left(45_{1}{ }^{\mathrm{A}} / 0_{3}{ }^{\mathrm{B}} / 45_{1}{ }^{\mathrm{A}}\right)$ & $152 \pm 9$ & $5.26 \pm 0.37$ & $0.036 \pm 0.001$ \\
\hline
\end{tabular}
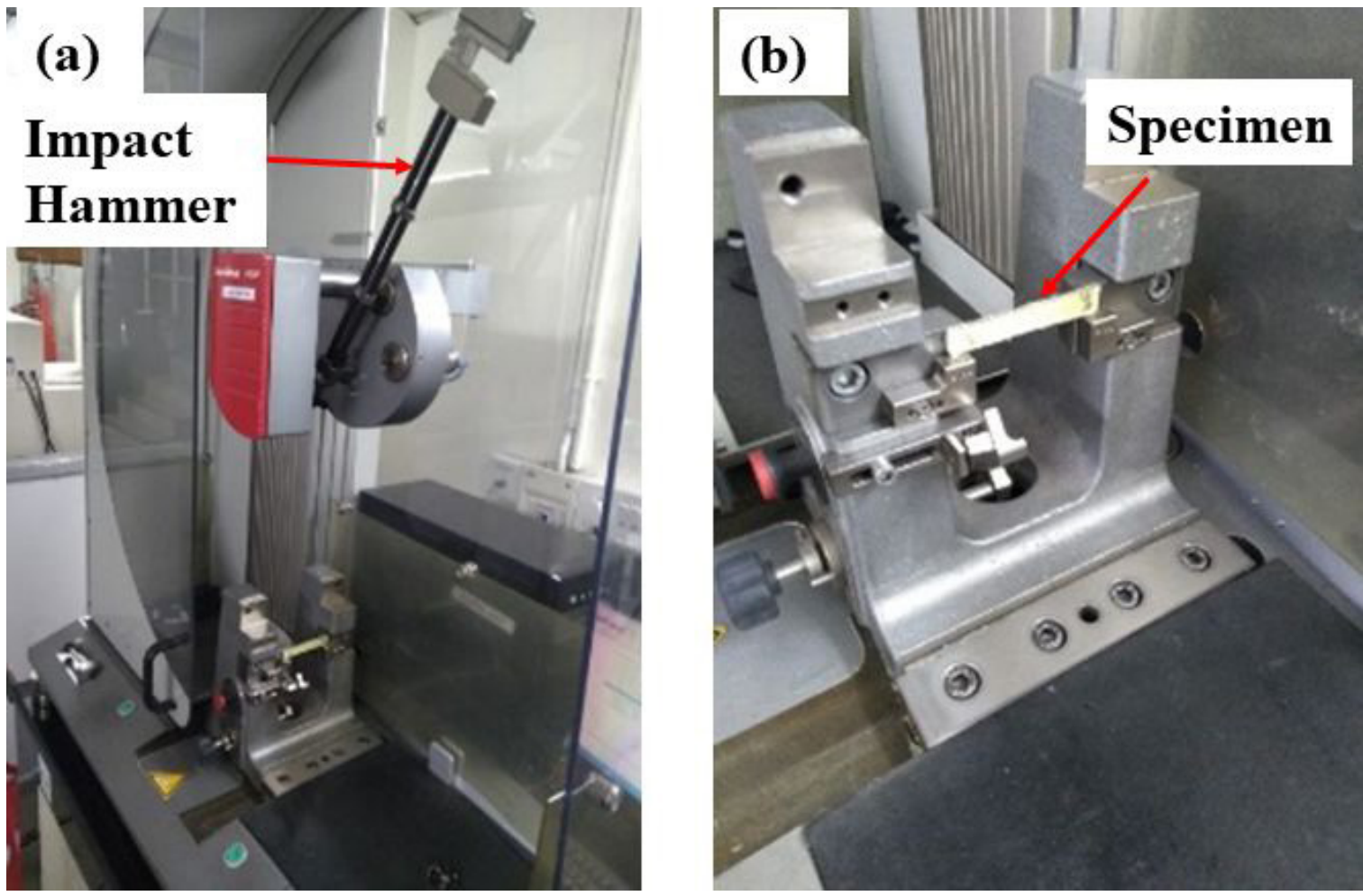

Figure 5. (a) Impact test setup (b) Specimen with specimen holder.

the maximum value of tensile strength for three different laminates $\left(0{ }_{1}^{\mathrm{A}} / 0_{3}{ }^{\mathrm{B}} / 0_{1}{ }^{\mathrm{A}}\right),\left(30{ }_{1}^{\mathrm{A}} / 0_{3}{ }^{\mathrm{B}} / 30_{1}{ }^{\mathrm{A}}\right)$ and $\left(45_{1}{ }^{\mathrm{A}} / 0_{3}{ }^{\mathrm{B}} / 45_{1}{ }^{\mathrm{A}}\right)$ is shown in Figure 6. The experimental results show that aramid fabric orientation angle has significant effect on the tensile properties of the laminates. Composites with the fibres aligned in $\left(0_{1}{ }^{\mathrm{A}} / 0_{3}{ }^{\mathrm{B}} / 0_{1} \mathrm{~A}\right)$ orientation angle showed higher tensile strength and modulus compared to $\left(30_{1}{ }^{\mathrm{A}} / 0_{3}{ }^{\mathrm{B}} / 30_{1}{ }^{\mathrm{A}}\right)$ and $\left(45_{1}{ }^{\mathrm{A}} / 0_{3}{ }^{\mathrm{B}} / 45_{1}{ }^{\mathrm{A}}\right)$ laminates. The average tensile strength and modulus of $\left(0_{1}{ }^{\mathrm{A}} / 0_{3}{ }^{\mathrm{B}} / 0_{1}{ }^{\mathrm{A}}\right)$ composites were $190.36 \mathrm{MPa}$ and 6.32 GPa respectively. $\left(45_{1}^{\mathrm{A}} / 0_{3}^{\mathrm{B}} / 45_{1}^{\mathrm{A}}\right)$ laminates possess the lowest strength and the modulus. $\left(0_{1}{ }^{\mathrm{A}} / 0_{3}{ }^{\mathrm{B}} / 0_{1}{ }^{\mathrm{A}}\right)$ laminates possess $14.47 \%$ higher tensile strength and $13.05 \%$ higher modulus compared to $\left(30_{1}{ }^{\mathrm{A}} / 0_{3}{ }^{\mathrm{B}} / 30_{1}^{\mathrm{A}}\right)$ laminates, $24.57 \%$ higher tensile strength and $20.15 \%$ higher modulus compared to $\left(45_{1}{ }^{\mathrm{A}} / 0_{3}{ }^{\mathrm{B}} / 45_{1}{ }^{\mathrm{A}}\right)$ laminates. This indicates that tensile strength and modulus decreases as the orientation angle of aramid fibres increases from the loading direction.

It can be seen from the stress-strain diagram that $\left(0_{1} \mathrm{~A} / 0_{3}{ }^{\mathrm{B}} / 0_{1} \mathrm{~A}\right)$ specimens exhibit lower strain under the tensile load when compared to other two orientations and $\left(45_{1}{ }^{\mathrm{A}} / 0_{3}{ }^{\mathrm{B}} / 45_{1}{ }^{\mathrm{A}}\right)$ specimens exhibit higher percentage deformation which is due the presence of long aramid fibre rovings in the diagonal direction.

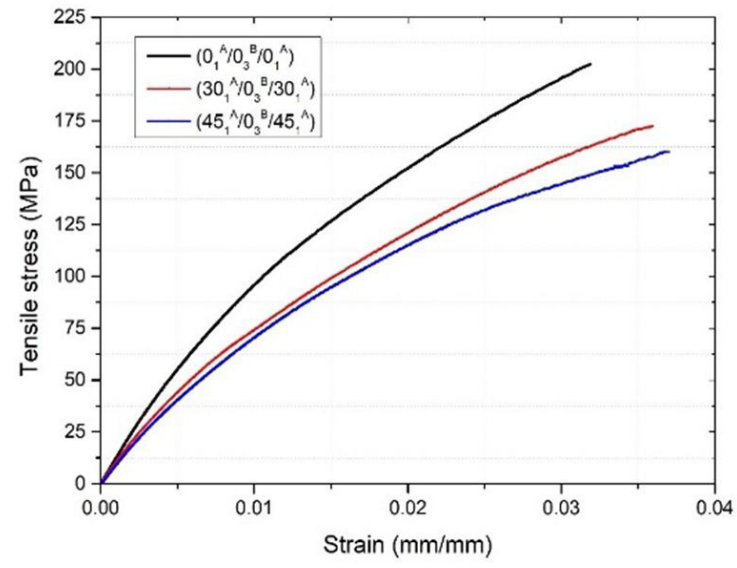

Figure 6. Stress-strain curves corresponding to maximum tensile strength values.

The fractured tensile test specimens of $\left(0_{1}{ }^{\mathrm{A}} / 0_{3}{ }^{\mathrm{B}} / 0_{1}{ }^{\mathrm{A}}\right)$, $\left(30_{1}{ }^{\mathrm{A}} / 0_{3}{ }^{\mathrm{B}} / 30_{1}{ }^{\mathrm{A}}\right)$ and $\left(45_{1}{ }^{\mathrm{A}} / 0_{3}{ }^{\mathrm{B}} / 45_{1}{ }^{\mathrm{A}}\right)$ are shown in Figure 7 .

The performance of $\left(0_{1}{ }^{\mathrm{A}} / 0_{3}{ }^{\mathrm{B}} / 0_{1} \mathrm{~A}\right)$ laminates was better when compared to $\left(30_{1}{ }^{\mathrm{A}} / 0_{3}{ }^{\mathrm{B}} / 30_{1}{ }^{\mathrm{A}}\right)$ and $\left(45_{1}{ }^{\mathrm{A}} / 0_{3}{ }^{\mathrm{B}} / 45_{1}{ }^{\mathrm{A}}\right)$ laminates 


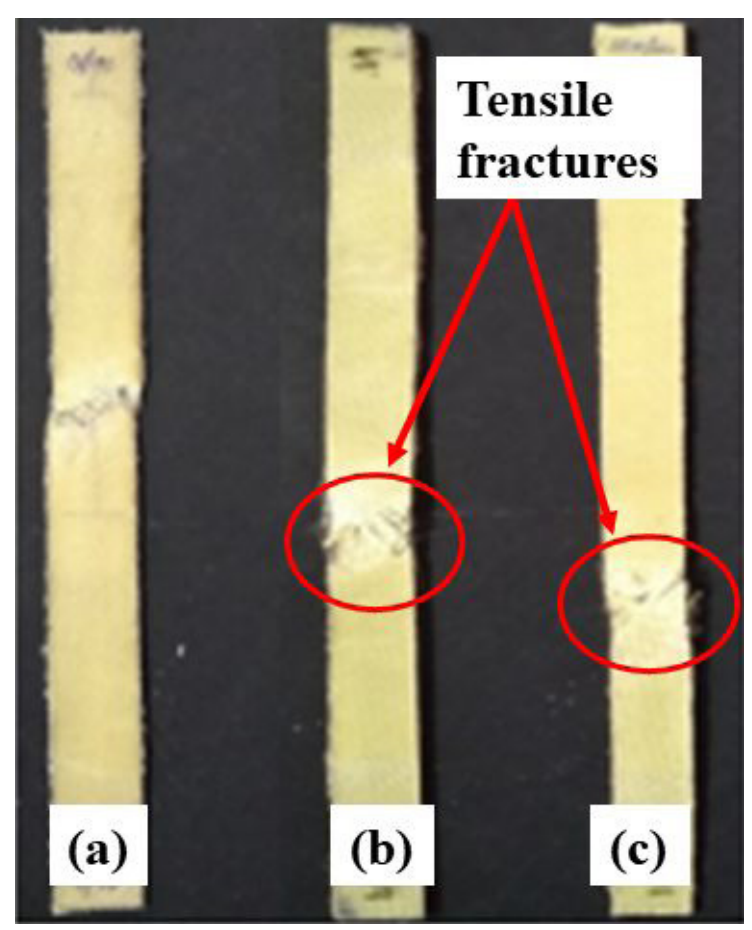

Figure 7. Fractured tensile test specimens (a) $\left(0_{1}{ }^{\mathrm{A}} / 0_{3}{ }^{\mathrm{B}} / 0_{1}{ }^{\mathrm{A}}\right)$ (b) $\left(30{ }_{1}^{\mathrm{A}} / 0_{3}{ }^{\mathrm{B}} / 30_{1}^{\mathrm{A}}\right)(\mathrm{c})\left(45_{1}{ }^{\mathrm{A}} / 0_{3}{ }^{\mathrm{B}} / 45_{1}{ }^{\mathrm{A}}\right)$. due to the fact that when aramid fibres are aligned in the direction of loading, specimen develops only tensile stresses. But when the fibres are oriented at an angle to the loading axis, composite forces are resolved into two components viz. tensile and shear forces. The interface between aramid and basalt develops higher shear stresses which results in shear strain of the material and delamination occurs. This reduces the load carrying capacity of the laminate. Also proper adhesion between the matrix and fibre attributes to the rise in tensile strength of the laminate. Another reason for the failure may be the polymer matrix dominates the tensile behaviour rather than the fibres due to the off axis loading of specimens.

\subsection{Micro structural studies of fractured tensile specimens}

SEM examinations help us in investigating the fracture behaviour of the failed specimens. Figure 8 shows the SEM micrographs of fractured tensile test specimens. Composite with minimum pull-out was observed in $\left(0_{1} \mathrm{~A} / 0_{3}{ }^{\mathrm{B}} / 0_{1} \mathrm{~A}\right)$ composites, this is due to strong bonded matrix which covered the fibres tightly and held the fibres in their position. As a result, pullout of the fibres minimised and higher tensile strength and modulus were observed owing to its strong interfacial bonding. This shows, the adhesion between fibre and matrix interface determines the tensile properties of the laminates.
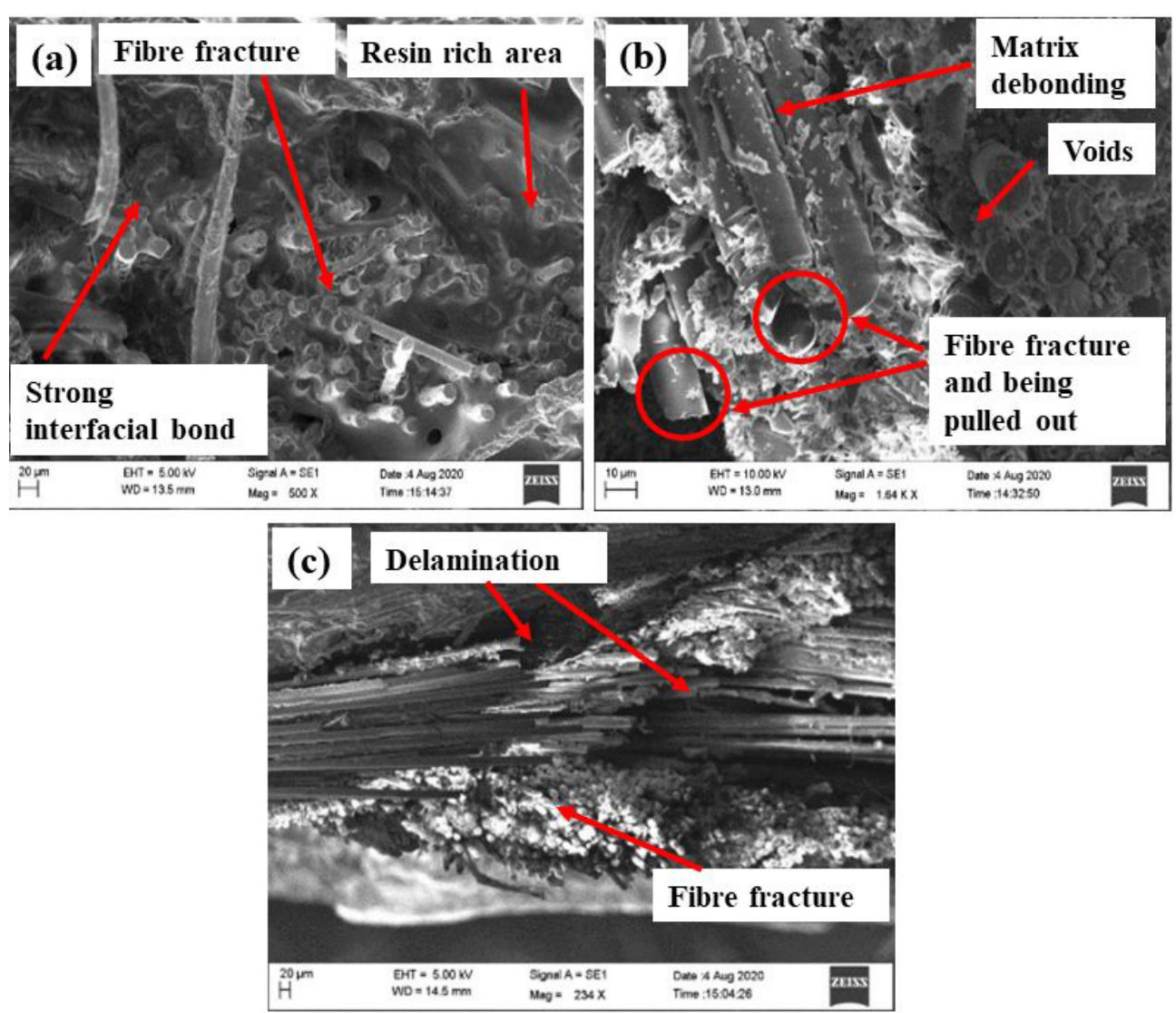

Figure 8. SEM micrographs of fractured tensile test specimens (a) $\left(0_{1}{ }^{\mathrm{A}} / 0_{3}{ }^{\mathrm{B}} / 0_{1}^{\mathrm{A}}\right) \operatorname{specimen}(\mathrm{b})\left(30_{1}{ }^{\mathrm{A}} / 0_{3}{ }^{\mathrm{B}} / 30_{1}^{\mathrm{A}}\right) \operatorname{specimen}(\mathrm{c})\left(45_{1}^{\mathrm{A}} / 0_{3}{ }^{\mathrm{B}} / 45_{1}{ }^{\mathrm{A}}\right)$ specimen. 
The reduced tensile strength of $\left(30_{1}{ }^{\mathrm{A}} / 0_{3} \mathrm{~B} / 30_{1}{ }^{\mathrm{A}}\right)$ and $\left(45_{1} \mathrm{~A} / 0_{3} \mathrm{~B} / 45_{1}^{\mathrm{A}}\right)$ specimens is due to the various modes of failures such as fibre fracture, matrix de-bonding and delamination as shown in Figure $8 \mathrm{~b}$ and $8 \mathrm{c}$. Also SEM examinations show occurrence of fibre pull-out which indicate poor bonding between fibre and matrix, which resulted in unsatisfactory performance of the composites. Delamination is the one type of failure mode observed in $\left(30_{1}{ }^{\mathrm{A}} / 0_{3}{ }^{\mathrm{B}} / 30_{1}{ }^{\mathrm{A}}\right)$ and $\left(45_{1}{ }^{\mathrm{A}} / 0_{3}{ }^{\mathrm{B}} / 45_{1}{ }^{\mathrm{A}}\right)$ composites, due to the induced shear stresses between the aramid-basalt laminate which initiated the matrix to take up more load than the fibres and led to matrix dominated failures. This generally happens when the fibres are not aligned in the direction of loading. Performance of the composites is also influenced by the efficacy of the fabrication method which is measured by void fraction. The reduced performance of $\left(30_{1}{ }^{\mathrm{A}} / 0_{3}{ }^{\mathrm{B}} / 30_{1}{ }^{\mathrm{A}}\right)$ and $\left(45_{1}{ }^{\mathrm{A}} / \mathrm{O}_{3}{ }^{\mathrm{B}} / 45_{1}{ }^{\mathrm{A}}\right)$ laminates could also be due to the presence of higher percentage of voids when compared to $\left(0_{1}{ }^{\mathrm{A}} / \mathrm{O}_{3}{ }^{\mathrm{B}} / 0_{1}{ }^{\mathrm{A}}\right)$ laminate.

Higher values of tensile strengths of $\left(0_{1}{ }^{\mathrm{A}} / \mathrm{O}_{3}{ }^{\mathrm{B}} / 0_{1}{ }^{\mathrm{A}}\right)$ laminates can also be described by analysing its fracture morphologies. Two phase type of fracture pattern was witnessed in case of $\left(0_{1}{ }^{\mathrm{A}} / \mathrm{O}_{3}{ }^{\mathrm{B}} / 0_{1}{ }^{\mathrm{A}}\right)$ composites. At first, debonding occurred at the interface of fibre and matrix. Then due to relatively low strength, matrix was broken. Finally, high tensile strength aramid fibres were fractured. Since the aramid fibres have higher tensile strength, so $\left(0_{1}{ }^{\mathrm{A}} / \mathrm{O}_{3} \mathrm{~B} / 0_{1}^{\mathrm{A}}\right)$ composites exhibited greater tensile strength in the loading direction. In $\left(30_{1}{ }^{\mathrm{A}} / 0_{3} \mathrm{~B} / 30_{1} \mathrm{~A}\right)$ and $\left(45_{1}{ }^{\mathrm{A}} / 0_{3}{ }^{\mathrm{B}} / 45_{1}{ }^{\mathrm{A}}\right)$ composites, longitudinal strengths were inferior to that of $\left(0_{1}{ }^{\mathrm{A}} / \mathrm{O}_{3}{ }^{\mathrm{B}} / 0_{1}{ }^{\mathrm{A}}\right)$ composites. This is due to the fact that in $\left(30{ }_{1} \mathrm{~A} / 0_{3} \mathrm{~B} / 30_{1}{ }^{\mathrm{A}}\right)$ and $\left(45_{1}{ }^{\mathrm{A}} / 0_{3}{ }^{\mathrm{B}} / 45_{1}{ }^{\mathrm{A}}\right)$ laminates, composite strength is mainly dominated by fibre-matrix interfaces and the concentration of defects are higher on these interfaces. However, in $\left(0_{1}{ }^{\mathrm{A}} / 0_{3}{ }^{\mathrm{B}} / 0_{1}{ }^{\mathrm{A}}\right)$ composites the comparatively high strength aramid fibres and weaker epoxy matrix controls the tensile strength.

\subsection{Flexural strength and interlaminar shear strength (ILSS)}

Both flexural and ILSS test results of 3 different hybrid interply composite specimens showed similar trend, with $\left(0_{1}{ }^{\mathrm{A}} / 0_{3}{ }^{\mathrm{B}} / 0_{1}{ }^{\mathrm{A}}\right)$ specimens showing higher strengths than $\left(30_{1}{ }^{\mathrm{A}} / 0_{3}{ }^{\mathrm{B}} / 30_{1}{ }^{\mathrm{A}}\right)$ and $\left(45_{1}{ }^{\mathrm{A}} / 0_{3}{ }^{\mathrm{B}} / 45_{1}{ }^{\mathrm{A}}\right)$ composites when subjected to flexural and pure shearing loads. The bending test results are as shown in Table 4. The failure of specimens in threepoint flexural test occurred primarily due to bending and shearing. All the specimens failed by cracking at the loading surface below the loading nose and also on the back surface as shown in Figure 9. When the specimens are subjected to flexural loading, they experience tensile forces on the support surface and compressive forces on the loading surface this resulted in bent and broken fibres at the back surface of the

Table 4. Flexural test results of hybrid composites.

\begin{tabular}{ccc}
\hline Composites & Average flexural strength $(\mathrm{MPa})$ & Average flexural modulus $(\mathrm{GPa})$ \\
\hline$\left(0_{1}^{\mathrm{A}} / 0_{3}{ }^{\mathrm{B}} / 0_{1}^{\mathrm{A}}\right)$ & $268 \pm 13$ & $\mathbf{3 1 . 4} \pm \mathbf{1 . 5}$ \\
\hline$\left(30_{1}{ }^{\mathrm{A}} / 0_{3}{ }^{\mathrm{B}} / 30_{1}^{\mathrm{A}}\right)$ & $244 \pm 10$ & $\mathbf{2 3 . 9} \pm \mathbf{1 . 1}$ \\
\hline$\left(45_{1}{ }^{\mathrm{A}} / 0_{3}{ }^{\mathrm{B}} / 45_{1}^{\mathrm{A}}\right)$ & $229 \pm 12$ & $\mathbf{2 0 . 4} \pm \mathbf{1 . 3}$ \\
\hline
\end{tabular}
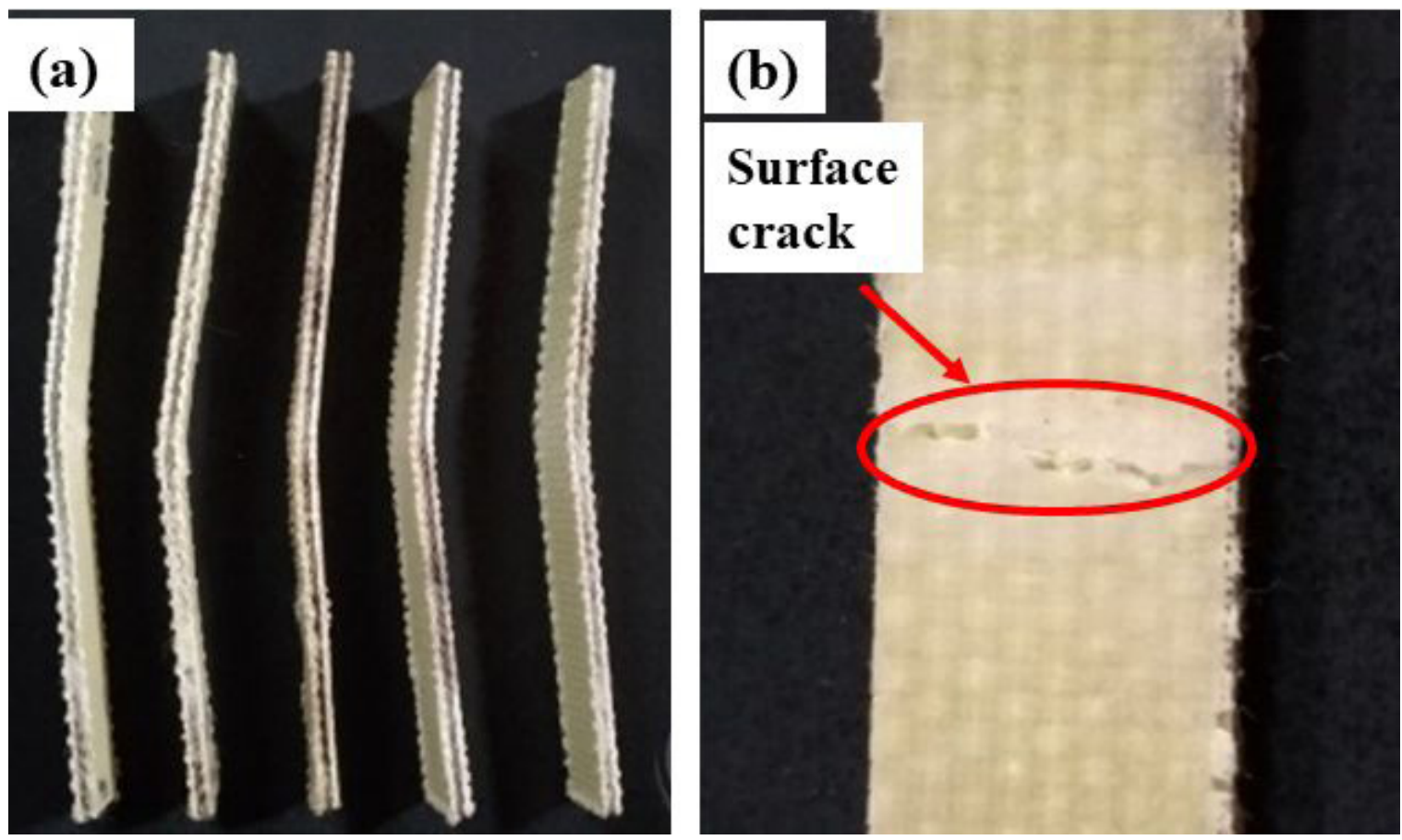

Figure 9. (a) Flexural test specimens after the test (b) Enlarged view of crack on the back surface. 
specimen. Hence, failure of the specimens is attributed to the surface cracks and delamination. It is observed that flexural strengths of the composites decrease with increase in the orientation angle of surface aramid fibres. This shows that shearing resistance of the composites decreased with increase in aramid fabric orientation angle. The highest average flexural strength and modulus observed were $268.32 \mathrm{MPa}$ and $31.41 \mathrm{GPa}$ respectively for the $\left(0_{1}{ }^{\mathrm{A}} / 0_{3}{ }^{\mathrm{B}} / 0_{1}{ }^{\mathrm{A}}\right)$ composites. $\left(45_{1}{ }^{\mathrm{A}} / 0_{3}{ }^{\mathrm{B}} / 45_{1}{ }^{\mathrm{A}}\right)$ laminates possess the lowest flexural strength. Specimens with $\left(0_{1}{ }^{\mathrm{A}} / 0_{3}{ }^{\mathrm{B}} / 0_{1}{ }^{\mathrm{A}}\right)$ orientation possess $9.73 \%$ higher flexural strength compared to $\left(30{ }_{1}{ }^{\mathrm{A}} / 0{ }_{3}^{\mathrm{B}} / 30_{1}{ }^{\mathrm{A}}\right)$ and $16.68 \%$ higher flexural strength compared to $\left(45_{1} \mathrm{~A} / 0_{3} \mathrm{~B} / 45_{1}^{\mathrm{A}}\right)$ laminates. This is due to the strain in each layer is directly impacted by the angle of fibre orientation. The deformation of each layer is directly proportional to the distance of the layer from the neutral axis as per the relative plane assumption of bending theory.

There are several factors which influences the flexural properties of composites. The most important factor is bonding strength between the fibre and matrix interface that helps in transferring the loads. Higher void percentage of the laminate has a detrimental effect on the flexural characteristics. Fibre orientation and fibre volume fractions are also considered as significant factors which affects the mechanical properties of the laminates.

It is noticed that tensile strengths and modulus are lower than the flexural strengths and modulus for all laminate orientations. These facts were proven empirically using the Wei bull probability analysis by Bullock and Dong and Davies $^{26,27}$.

$\frac{\sigma_{b}}{\sigma_{t}}=\left[2(\beta+1)^{2} \frac{m_{t}}{m_{b}}\right]^{\frac{1}{\beta}}$

Where $\sigma_{\mathrm{t}}$ and $\sigma_{\mathrm{b}}$ are the maximum values of tensile and flexural strengths respectively, $\beta$ is called the shape parameter, strength scatter will be less for higher values of $\beta$ and vice versa $^{28}$. The value of $\beta$ is always greater than one as per two parameter Weibull distribution. Also the mass of the stressed specimen in tensile loading is less than or equal flexural specimen, since \% elongation is higher in tensile specimen than the flexural. Hence $\sigma_{b}>\sigma_{t}$ from Equation 3 for all the orientations

ILSS test results of 3 different hybrid composite specimens are shown in Figure 10. From the figure it is evident that shear response of the specimens is strongly dependent on the orientation angle of the surface aramid fibre and it decreases as the fibre orientation angle increases with respect to loading direction. The ILSS fixture was designed such that it generates a simple shear state by minimising tensile, bending and compressive influences. This results in parallel faces of the specimens to slide in opposite directions, generating horizontal cracks and delamination. Optical microscope images of the tested specimens are shown in Figure 11. All the failed specimens exhibited interlaminar cracks at the mid plane and delamination between the laminae. The $\left(0_{1}{ }^{\mathrm{A}} / 0_{3}{ }^{\mathrm{B}} / 0_{1}{ }^{\mathrm{A}}\right)$ specimens were able to withstand higher amount of shear load than other samples which is a strong evidence of the effect of aramid fibre orientation angle on this test. The $\left(0_{1}{ }^{\mathrm{A}} / 0_{3}{ }^{\mathrm{B}} / 0_{1}{ }^{\mathrm{A}}\right)$ laminates showed higher ILSS, which

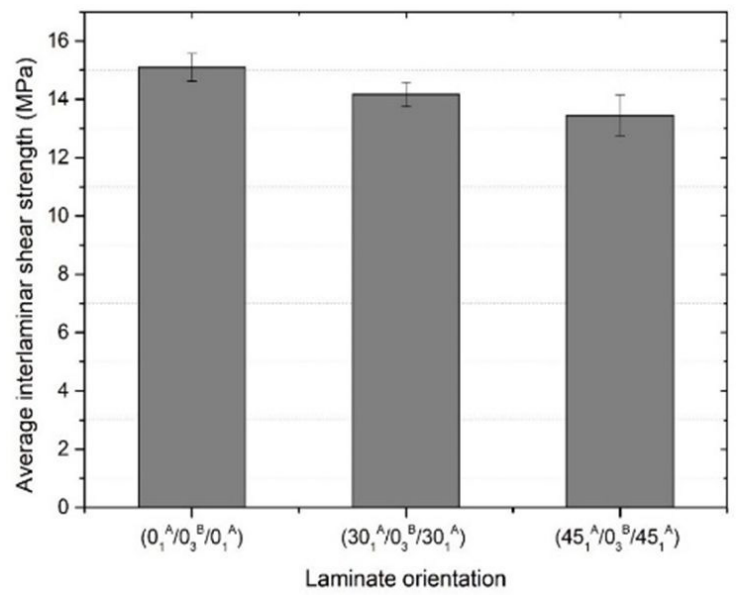

Figure 10. Average ILSS of hybrid laminates.

was $15.10 \mathrm{MPa}$ followed by $\left(30_{1}{ }^{\mathrm{A}} / 0_{3}{ }^{\mathrm{B}} / 30_{1}{ }^{\mathrm{A}}\right)$ and $\left(45_{1}{ }^{\mathrm{A}} / 0_{3}{ }^{\mathrm{B}} / 45_{1}{ }^{\mathrm{A}}\right)$ laminates, which were $14.17 \mathrm{MPa}$ and $13.45 \mathrm{MPa}$ respectively. The $\left(45_{1}{ }^{\mathrm{A}} / 0_{3}{ }^{\mathrm{B}} / 45_{1}{ }^{\mathrm{A}}\right)$ specimens showed least value of ILSS. The $\left(0_{1}{ }^{\mathrm{A}} / 0_{3}{ }^{\mathrm{B}} / 0_{1}{ }^{\mathrm{A}}\right)$ laminates possess $6.56 \%$ higher ILSS when compared to $\left(30_{1}{ }^{\mathrm{A}} / 0_{3}{ }^{\mathrm{B}} / 30_{1}{ }^{\mathrm{A}}\right)$ and $12.26 \%$ higher ILSS when compared to $\left(45_{1}{ }^{\mathrm{A}} / 0_{3}^{\mathrm{B}} / 45_{1}^{\mathrm{A}}\right)$ composites.

\subsection{Impact strength}

Charpy impact test is a quick and cost effective technique for comparing the impact strength of different materials. The total amount of energy absorbed by the material during an impact is termed as impact strength which is a measure of material's brittleness. Multiple factors can influence the impact strength of hybrid composites, most importantly: strength and stiffness of the reinforcement, toughness of the matrix, thickness of the laminate, fibre orientation and layup sequence. The Charpy impact test was conducted to study the influence of aramid fabric orientation angle on the impact behaviour and failure modes of basalt-aramid /epoxy hybrid composites as per impact procedure ISO 179-1. The mode of impact damages were analysed using optical microscope to understand the deformation behaviour of the composites.

Composites absorb part of the total energy through elastic deformation and the remaining energy is utilised through various failure modes such as matrix crack, delamination, fibre break etc. Figure 12 shows the average impact strength of the specimens measured. Maximum impact resistance was observed for $\left(0_{1}{ }^{\mathrm{A}} / 0_{3}{ }^{\mathrm{B}} / 0_{1}{ }^{\mathrm{A}}\right)$ laminates, which was $128.86 \mathrm{~kJ} / \mathrm{m}^{2}$, followed by $\left(30_{1}{ }^{\mathrm{A}} / 0_{3}{ }^{\mathrm{B}} / 30_{1}{ }^{\mathrm{A}}\right)$ and $\left(45_{1}{ }^{\mathrm{A}} / 0_{3}{ }^{\mathrm{B}} / 45_{1}{ }^{\mathrm{A}}\right)$ composites, which were 116.23 and $109.57 \mathrm{~kJ} / \mathrm{m}^{2}$ respectively. Impact strength of $\left(0_{1}{ }^{\mathrm{A}} / 0_{3}{ }^{\mathrm{B}} / 0_{1}{ }^{\mathrm{A}}\right)$ specimen is $10.86 \%$ higher than $\left(30{ }_{1}{ }^{\mathrm{A}} / 0_{3}{ }^{\mathrm{B}} / 30_{1}{ }^{\mathrm{A}}\right)$ specimens and $17.6 \%$ higher than $\left(45_{1}{ }^{\mathrm{A}} / 0_{3}{ }^{\mathrm{B}} / 45_{1}{ }^{\mathrm{A}}\right)$ specimens. In other words, the surface aramid fibres oriented at $\left(0^{\circ} / 90^{\circ}\right)$ has showed better distribution of shock load than other aramid fibre orientation. Specimens with $\left(45_{1}{ }^{\mathrm{A}} / \mathrm{O}_{3} \mathrm{~B} / 45_{1}{ }^{\mathrm{A}}\right)$ orientation angle showed the least ability to absorb the dynamic impact load compared to other orientations. This indicates that surface fabric orientation angle considerably affects the impact strength and followed same trend as the tensile, flexural and ILSS test. Vasudevan et.al ${ }^{29}$. also studied the influence of Kevlar fibre alignment on low velocity impact 

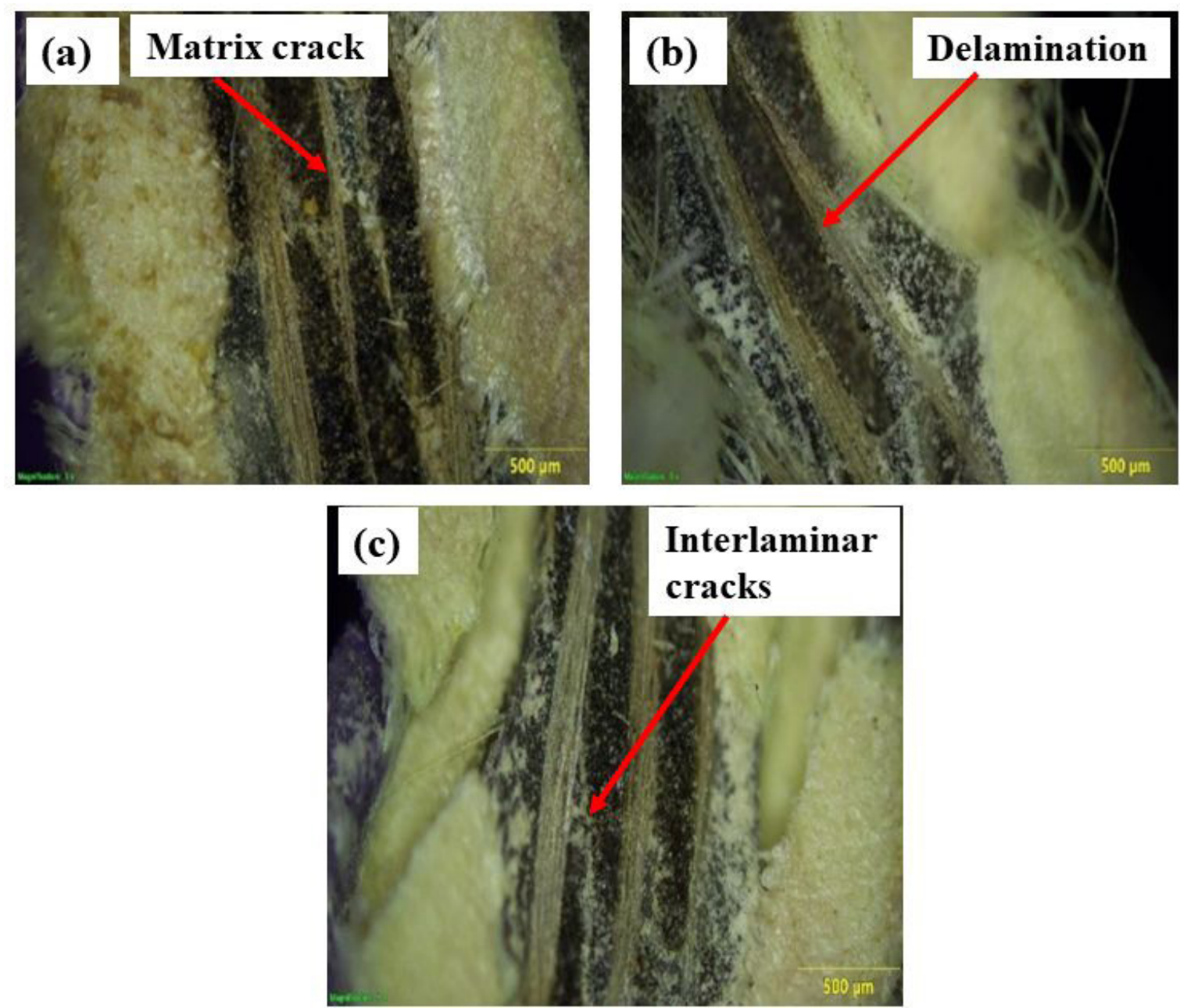

Figure 11. Optical microscope images of (a) $\left(0_{1}{ }^{\mathrm{A}} / 0_{3}{ }^{\mathrm{B}} / 0_{1}{ }^{\mathrm{A}}\right)$ (b) $\left(30_{1}{ }^{\mathrm{A}} / 0_{3}{ }^{\mathrm{B}} / 30_{1}{ }^{\mathrm{A}}\right)$ and (c) $\left(45_{1}{ }^{\mathrm{A}} / 0_{3}{ }^{\mathrm{B}} / 45_{1}{ }^{\mathrm{A}}\right)$ ILSS specimens.

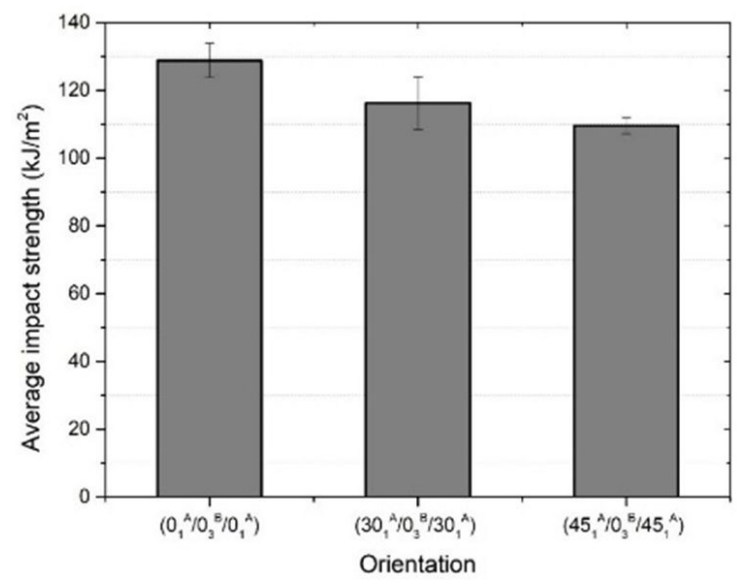

Figure 12. Average impact strength of hybrid laminates.

behaviour of fibre glass/epoxy composites and reported that $\left(30^{\circ} / 60^{\circ}\right)$ oriented surface Kevlar hybrid laminates absorbed higher impact and activation energies compared to hybrid laminated with $\left(45^{\circ} /-45^{\circ}\right)$ surface Kevlar orientation.
Various literatures have reported that addition of aramid fibres as face sheets improved the impact strength of hybrid composites $^{30}$. The optical microscope images were taken to analyse the failure characteristics of fractured impact samples as shown in Figure 13. The energy due to impact of aramid fibre layers is primarily absorbed by the debonding between the fibre and the matrix and delamination at the interface between the layers. The damage analysis of basalt-aramid layers showed that the extent of delamination between the aramid and basalt fibre was lower in case of $\left(0_{1}{ }^{\mathrm{A}} / 0_{3}{ }^{\mathrm{B}} / 0_{1}{ }^{\mathrm{A}}\right)$ laminates than $\left(30_{1}{ }^{\mathrm{A}} / 0_{3}{ }^{\mathrm{B}} / 30_{1}{ }^{\mathrm{A}}\right)$ and $\left(45_{1}{ }^{\mathrm{A}} / 0_{3}{ }^{\mathrm{B}} / 45_{1}{ }^{\mathrm{A}}\right)$ laminates. Also much stronger bond was observed in case of $\left(0_{1}{ }_{1}^{\mathrm{A}} / 0_{3}{ }^{\mathrm{B}} / 0_{1}{ }^{\mathrm{A}}\right)$ laminates. The most important damage mechanisms observed at the back surface of the samples were delamination, cracking of matrix and fibre breakage. The damage of fibre layers at the back surface (tensile side) of the hybrid samples were initiated by tensile failure. Hence, the tensile characteristics of the material located at the back surface plays an important role in controlling the impact strength and damage mechanism of the laminates. The impact strength of basalt laminates increases by the hybridisation of aramid surface fibres, 

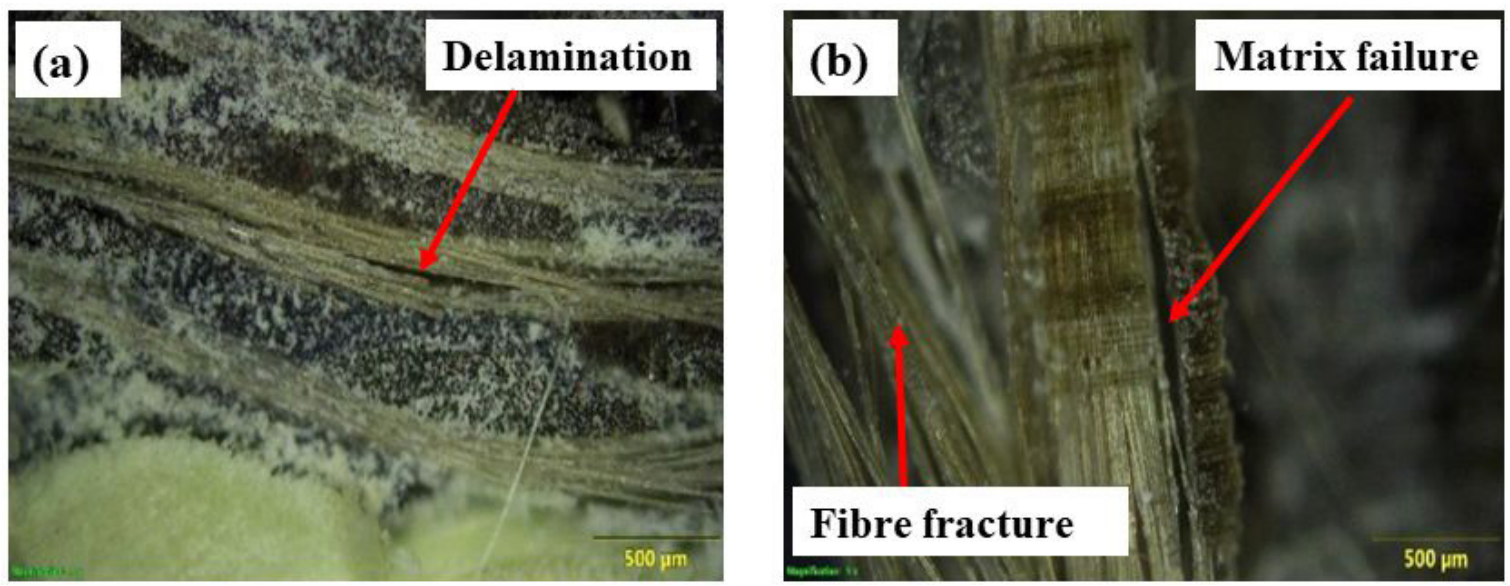

Figure 13. Optical microscope images of fractured (a) $\left(0_{1}{ }^{\mathrm{A}} / 0_{3}{ }^{\mathrm{B}} / 0_{1}{ }^{\mathrm{A}}\right)$

(b) $\left(45_{1}{ }^{\mathrm{A}} / 0_{3}^{\mathrm{B}} / 45_{1}^{\mathrm{A}}\right)$ impact specimens.

which results in higher deformation and flexural stiffness of the composite due to higher ductility of the aramid fibres.

Fractured specimens revealed higher amount of damage on its bottom surface than on the top surface. $\operatorname{In}\left(0_{1}{ }^{\mathrm{A}} / 0_{3}{ }^{\mathrm{B}} / 0_{1}{ }^{\mathrm{A}}\right)$ laminates, damage is distributed over the larger area and less concentrated damage was seen at the impacted zone. It implies that the presence of $0^{\circ}$ angle oriented aramid ply on the outer surface protects the core basalt plies by spreading out the impact damage to more area and controls the delamination. The overall damage area was more for $\left(0_{1} \mathrm{~A} / 0_{3}{ }^{\mathrm{B}} / 0_{1}{ }^{\mathrm{A}}\right)$ laminates, which led to higher impact energy absorption capability when compared to $\left(30{ }_{1}{ }^{\mathrm{A}} / 0_{3}{ }^{\mathrm{B}} / 30_{1}{ }^{\mathrm{A}}\right)$ and $\left(45_{1}{ }^{\mathrm{A}} / 0_{3}{ }^{\mathrm{B}} / 45_{1}{ }^{\mathrm{A}}\right)$ laminates. Core layers are significantly less affected by the damage compared to surface layers due to less significant bending stresses at the neutral layers.

\section{Conclusion}

In the present work, effect of aramid fabric orientation angle viz. $\left(0{ }_{1}{ }^{\mathrm{A}} / 0_{3}{ }^{\mathrm{B}} / 0_{1}{ }^{\mathrm{A}}\right),\left(30_{1}{ }^{\mathrm{A}} / 0_{3}{ }^{\mathrm{B}} / 30_{1}{ }^{\mathrm{A}}\right)$ and $\left(45_{1}{ }_{1}^{\mathrm{A}} / 0_{3}{ }^{\mathrm{B}} / 45_{1}{ }^{\mathrm{A}}\right)$ on the mechanical characteristics of basalt-aramid /epoxy hybrid composites has been investigated. The specimens were fabricated using compression molding process and mechanical tests were carried out as per ASTM standards.

- Laminates with fibre orientation angle of $\left(0_{1}{ }^{\mathrm{A}} / 0_{3}{ }^{\mathrm{B}} / 0_{1}{ }^{\mathrm{A}}\right)$ possess $24.07 \mathrm{MPa}$ higher tensile strength compared to $\left(30_{1}{ }^{\mathrm{A}} / 0_{3}{ }^{\mathrm{B}} / 30_{1}{ }^{\mathrm{A}}\right)$ laminates and $37.55 \mathrm{MPa}$ higher tensile strength compared to $\left(45_{1} \mathrm{~A} / 0_{3}{ }^{\mathrm{B}} / 45_{1}{ }^{\mathrm{A}}\right)$ laminates.

- $\quad\left(45_{1} \mathrm{~A} / 0_{3}{ }^{\mathrm{B}} / 45_{1}^{\mathrm{A}}\right)$ laminates exhibited higher percentage strain due to the long diagonal aramid fibre rovings and least percentage elongation was observed in $\left(0_{1}{ }^{\mathrm{A}} / 0_{3}{ }^{\mathrm{B}} / 0_{1}{ }^{\mathrm{A}}\right)$ specimens.

- Laminates with fibre orientation angle of $\left(0_{1}{ }^{\mathrm{A}} / 0_{3}{ }^{\mathrm{B}} / 0_{1}{ }^{\mathrm{A}}\right)$ possess 23.81 MPa higher flexural strength compared to $\left(30{ }^{\mathrm{A}} / 0_{3}{ }^{\mathrm{B}} / 30^{\mathrm{A}}\right)$ laminates and $38.36 \mathrm{MPa}$ higher flexural strength compared to $\left(45_{1}{ }^{\mathrm{A}} / 0_{3}{ }^{\mathrm{B}} / 45_{1}{ }^{\mathrm{A}}\right)$ laminates.

- $\quad\left(0_{1}{ }^{\mathrm{A}} / 0_{3}{ }^{\mathrm{B}} / 0_{1}{ }^{\mathrm{A}}\right)$ laminates possess $6.53 \%$ higher ILSS when compared to $\left(30{ }^{\mathrm{A}} / 0_{3}{ }^{\mathrm{B}} / 30^{\mathrm{A}}\right)$ and $12.28 \%$ higher ILSS when compared to $\left(45_{1}{ }^{\mathrm{A}} / 0_{3}{ }^{\mathrm{B}} / 45_{1}{ }^{\mathrm{A}}\right)$ laminates.
- $\quad\left(0_{1}{ }^{\mathrm{A}} / \mathrm{O}_{3}{ }^{\mathrm{B}} / 0_{1}{ }^{\mathrm{A}}\right)$ laminates were found to absorb higher impact loads due to better distribution of shock loads and possess $10.86 \%$ of higher impact strength compared to $\left(30_{1}{ }^{\mathrm{A}} / 0_{3} \mathrm{~B} / 30_{1}^{\mathrm{A}}\right)$ and $17.6 \%$ higher impact strength compared to $\left(45_{1}{ }^{\mathrm{A}} / 0_{3}{ }^{\mathrm{B}} / 45_{1}{ }^{\mathrm{A}}\right)$ laminates.

- $\quad$ SEM micrographs of fractured tensile test samples showed various damages mechanisms such as fibre pull out, fibre fracture and matrix de-bonding. Delamination is found to be the major failure mode due to the shear effect in $\left(30_{1}{ }^{\mathrm{A}} / 0_{3}{ }^{\mathrm{B}} / 30_{1}{ }^{\mathrm{A}}\right)$ and $\left(45_{1}{ }^{\mathrm{A}} / 0_{3}{ }^{\mathrm{B}} / 45_{1}{ }^{\mathrm{A}}\right)$ laminates subjected to static loading conditions.

- Results suggest that $\left(0_{1}{ }^{\mathrm{A}} / 0_{3}{ }^{\mathrm{B}} / 0_{1}{ }^{\mathrm{A}}\right)$ laminates possess improved mechanical properties compared to other orientation angle and can be recommended for structural applications such as automobile bumpers, aircraft wing structures and bullet proof jackets.

\section{References}

1. Ye HZ, Liu XY, Kiran GB, Suman KNS, Rao NM, Rao RUM. Mechanical properties and production quality of hand-layup and vacuum infusion processed hybrid composite materials for GFRP marine structures. Ind Robot An Int J. 2016;5(3):1-2.

2. Chawla KK. Composite materials: science and engineering. 3rd ed. New York: Springer Science \& Business Media; 2012.

3. Muñoz R, Martínez V, Sket F, González C, Llorca J. Mechanical behavior and failure micromechanisms of hybrid 3D woven composites in tension. J. Composites A. 2014;59:93-104.

4. Nunna S, Chandra PR, Shrivastava S, Jalan AK. A review on mechanical behavior of natural fiber based hybrid composites. J Reinf Plast Compos. 2012;31(11):759-69.

5. Nur S, Safri A, Thariq M, Sultan H. Characterization of benzoyl treated sugar palm/glass fibre hybrid composites. Integr Med Res. 2020;9(5):11563-73.

6. Shaid A, Ahsan M, Zoynal M. Experimental investigation of the mechanical and water absorption properties on fiber stacking sequence and orientation of jute/carbon epoxy hybrid composites. Integr Med Res. 2020;9(5):10970-81.

7. Arpatappeh FA, Azghan MA, Eslami-Farsani R. The effect of stacking sequence of basalt and Kevlar fibers on the Charpy 
impact behavior of hybrid composites and fiber metal laminates. Proc Inst Mech Eng, C J Mech Eng Sci. 2020;234(16):3270-9.

8. Dhand V, Mittal G, Rhee KY, Park S-J, Hui D. A short review on basalt fiber reinforced polymer composites. Compos, Part B Eng. 2015;73:166-180.

9. Khandelwal S, Rhee KY. Recent advances in basalt-fiberreinforced composites : tailoring the fiber-matrix interface. Compos Part B. 2020;192:108011.

10. Fiore V, Scalici T, Di Bella G, Valenza A. A review on basalt fibre and its composites. Compos, Part B Eng. 2015;74:74-94.

11. Tehrani M, Nosraty H, Mehrdad M, Minak G, Ghelli D. The influence of hybridization on impact damage behavior and residual compression strength of intraply basalt/nylon hybrid composites. J Mater. 2013;43:283-90.

12. Wang X, Hu B, Feng Y, Liang F, Mo J, Xiong J, et al. Low velocity impact properties of $3 \mathrm{D}$ woven basalt/aramid hybrid composites. Compos Sci Technol. 2008;68(2):444-50.

13. Bandaru AK, Patel S, Sachan Y, Ahmad S, Alagirusamy R, Bhatnagar N. Mechanical behavior of Kevlar/basalt reinforced polypropylene composites. Compos, Part A Appl Sci Manuf. 2016;90:642-52.

14. Sarasini F, Tirillò J, Ferrante L, Valente M, Valente T, Lampani L, et al. Drop-weight impact behaviour of woven hybrid basaltcarbon/epoxy composites. Compos, Part B Eng. 2014;59:204-20.

15. Sarasini F, Tirillò J, Valente $M$, Valente T, Cioffi S, Iannace $\mathrm{S}$, et al. Effect of basalt fiber hybridization on the impact behavior under low impact velocity of glass/basalt woven fabric/epoxy resin composites. Compos, Part AAppl Sci Manuf. 2013;47(1):109-23.

16. Sarasini F, Tirillò J, Valente M, Ferrante L, Cioffi S, Iannace $\mathrm{S}$, et al. Hybrid composites based on aramid and basalt woven fabrics: impact damage modes and residual flexural properties. Mater Des. 2013;49:290-302.

17. Park R, Jang J. Impact behavior of aramid fiber/glass fiber hybrid composite: evaluation of four-layer hybrid composites. J Mater Sci. 2001;36(9):2359-67.

18. Vasudevan A, Kumaran SS, Naresh K, Velmurugan R, Shankar K, Kumaran SS. Advanced 3D and 2D damage assessment of low velocity impact response of glass and Kevlar fiber reinforced epoxy hybrid composites. Adv Mater Process Technol. 2018;0698:1-18.
19. Dorey G, Sidey GR, Hutchings J. Impact properties of carbon fibre/Kevlar 49 fibre hydrid composites. Composites. 1978;9(1):25-32.

20. American Society for Testing \& Materials - ASTM. ASTM D792-20: standard test methods for density and specific gravity (relative density) of plastics by displacement. West Conshohocken: ASTM; 2013.

21. Agarwal BD, Broutman LJ. Analysis and performance of fiber composites. 2nd ed. Hoboken: John Wiley \& Sons; 1990.

22. American Society for Testing \& Materials - ASTM. ASTM D3039/D3039M-14: standard test method for tensile properties of polymer matrix composite. West Conshohocken: ASTM; 2014.

23. American Society for Testing \& Materials - ASTM. ASTM D7264/D7264M-07: standard test method for flexural properties of polymer matrix composite materials. West Conshohocken: ASTM; 2007.

24. American Society for Testing \& Materials - ASTM. ASTM D2344/D2344M-13: standard test method for short-beam strength of polymer matrix composite materials and their laminates. West Conshohocken: ASTM; 2013.

25. International Organisation for Standardization - ISO. ISO 179-1: plastics: determination of Charpy impact properties. Part 1: non-instrumented impact test. Geneva: ISO; 2000.

26. Bullock RE. Strength ratios of composite materials in flexure and in tension. J Compos Mater. 1974;8(2):200-6.

27. Dong C, Davies IJ. Optimal design for the flexural behaviour of glass and carbon fibre reinforced polymer hybrid composites. J Mater. 2012;37:450-7.

28. Naresh K, Shankar K, Velmurugan R. Reliability analysis of tensile strengths using Weibull distribution in glass/epoxy and carbon / epoxy composites. Compos Part B. 2018;133:129-44.

29. Vasudevan A, Senthil Kumaran S, Naresh K, Velmurugan R, Shankar K. Advanced 3D and 2D damage assessment of low velocity impact response of glass and Kevlar fiber reinforced epoxy hybrid composites. Adv Mater Process Technol. 2018;4(3):493-510.

30. Erkliğ A, Bulut M. Experimental investigation on tensile and Charpy impact behavior of Kevlar/S-glass/epoxy hybrid composite laminates. J Polym Eng. 2017;37(2):177-84. 